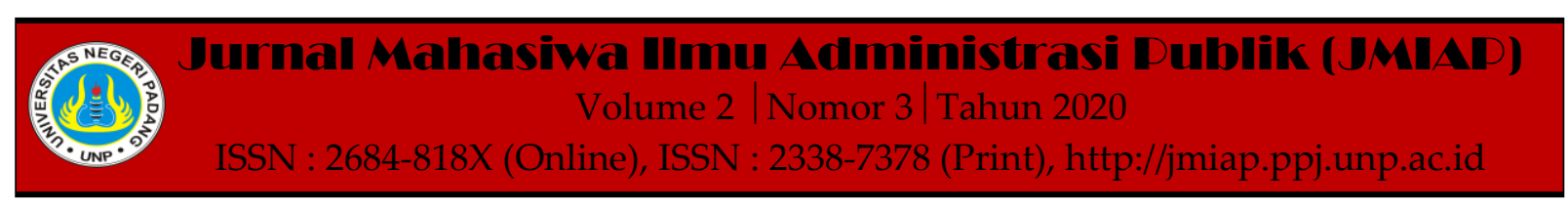

\title{
IMPLEMENTASI PEMBANGUNAN PEDESTRIAN JALAN KHATIB SULAIMAN KOTA PADANG
}

\author{
Muthia Claudia Ulfa ${ }^{1(a)}$, Nora Eka Putri ${ }^{2(b)}$ \\ ${ }^{1}$ Jurusan Ilmu Administrasi Negara, Universitas Negeri Padang \\ ${ }^{2}$ Jurusan Ilmu Administrasi Negara, Universitas Negeri Padang \\ ${ }^{a)}$ muthiaclaudiaulfa@gmail.com, ${ }^{b)}$ noraekaputri@fis.unp.ac.id
}

\begin{abstract}
The purpose of this study is to analyze the implementation of pedestrian improvement at khatib sulaiman street, Padang city and to identify the inhibiting factors of pedestrian improvement at khatib sulaiman street, Padang City. And to identify the inhibiting factors of pedestrian improvement at Khatib Sulaiman street, Padang city. pedestrian is an activity or human movement from one place to another by foot, or in other words, a pedestrian is a person walking on the street pedestrian network facilities and infrastructure generally function to facilitate the movement of pedestrian from one place to another easily, smoothly, safely, comfortably and independently. This research was a qualitative research which related to descriptive phenomena, events, social activities, techniques, interviews, and documentation. The data was analyzed throught data reduction and drawing conclusion. The results of this study indicated that there was not yet benefit showed related to the changes desired by government and society toward pedestrian. The factors that emerged on the performance, the existence of adequate pedestrian but lack of cummunicy awareness of using the facilities itself.
\end{abstract}

Keywords : Implementating, Development, Pedestrian

Corresponding author. Email. muthiaclaudiaulfa@gmail.com,noraekaputri@fis.unp.ac.id

How to cite this article. Ulfa, M. Claudia \& Putri, N. Eka. (2020). Implementasi Pembangunan Pedestrian Jalan Khatib Sulaiman Kota Padang. Jurnal Mahasiwa Ilmu Administrasi Publik (JMIAP) Jurusan Ilmu Administrasi Negara Fakultas Ilmu Sosial Universitas Negeri Padang, Volume 2 (3), Hal. $1-8$.

http://jmiap.ppj.unp.ac.id

ISSN : 2684-818X (Online), ISSN : 2338-7378 (Print)

Copyright $\odot 2020$. Published by Labor Jurusan Ilmu Administrasi Negara FIS UNP, Padang 


\section{PENDAHULUAN}

Kualitas jalur pedestrian adalah tingkat baik atau buruknya suatu jalur pedestrian yang dapat dilihat dari bagaimana pejalan kaki dapat berjalan dan menggunakan pedestrian sesuai fungsinya dengan merasa aman dan nyaman, pedestrian memberi fungsi besar sebagai pemacu perkembangan perekonomian kota khususnya terhadap bisnis-bisnis retail dan pusat perbelanjaan. Hal ini karena berjalan sambil belanja merupakan salah satu atraksi wisata utama pada kehidupan perkotaan. (Suthreerakul et al: 2017).

Jalan khatib sulaiman salah satu jalan utama yang ada di pusat kota Padang. Jalan ini langsung berhubung dengan jalan S.Parman yang merupakan jalan masuk utama dari kota/kabupaten bagian utara Provinsi Sumatera Barat untuk menuju kota Padang. Jalan Khatib sulaiman sebagai salah satu jalan utama di kota Padang membuat arus lalu lintas dan pergerakan manusia di jalan ini sangat ramai. Tidak hanyak pergerakan manusia yang menggunakan kendaraan, namun juga para pejalan kaki yang bergerak di jalur pedestrian. Jalan ini juga merupakan pusat perkantoran dan sekarang sudah menjadi pusat perbelanjaan juga menjadikan karekteristik bangunan di sepanjang koridor jalan tersebut adalah bangunan yang bersifat publik.

Jalan Khatib Sulaiman merupakan kawasan pusat perkantoran pemerintah provinsi serta tempat perbelanjaan dan lokasi bisnis di Kota Padang. Letak Jalan Khatib Sulaiman yang berada pada kawasan perkantoran dan kawasan komersial tersebut menjadikan karakteristik bangunan di sepanjang koridor jalan tersebut adalah bangunan yang bersifat publik. Pernahkan kita berpikir bahwa untuk menciptakan suatu kawasan perkantoran yang nyaman tentunya selain ruas jalannya tidak macet oleh kendaraan juga tidak adanya hambatan lain semisal parkir di pinggir jalan (on street parking) walaupun tidak ada larangan parkir di sisi jalan. (Rahmi, 2018).
Masih terjadi parkir dipinggir jalan terutama pada ruas-ruas jalan untama notabene adalah kawasan perkantoraan (yang harusnya bebas macet) dan salah satu penyebab kemacetan adalah pusat komersial bisnis, jika diamati ternyata hal ini diakibatkan banyak kantor yang tidak cukup memiliki pelataran parkir dengan daya tampung parkir yang memadahi. Koordinsi koalisi masyarakat peduli kota Padang mengatakan, peruntukan ruang pemanfaatan sepanjang jalan khatib sulaiman kota Padang merujuk pasa ketentuan pasal 70 ayat (3) peraturan daerah Tahun 2012 tentang rencana tata ruang wilayah kota Padang menyebutkan bahwa: perkantoran pemerintah provinsi dikembangkan pada lokasi yang sudah berkembang saat ini, yaitu koridor jalan jendral sudirman dan jalan jalan khatib sulaiman kota Padang.

Pemerintah Kota Padang melalui Dinas Pekerjaan Umum Penataan Ruang melakukan pembangunan pembetonan dan rehabilitasi trotoar sepanjang 8,8 kilometer yang tersebar di sejumlah titik di Kota Padang. Hal ini seiring dengan peningkatan pelayanan bagi pejalan kaki serta sebagai bentuk penunjang dalam mewujudkan masyarakat yang madani, pengerjaan pembuatan pedestrian trotoar di Jalan Khatib Sulaiman sudah berjalan 20 persen. Sepanjang $1 \mathrm{~km}$ dengan lebar 6-8 $\mathrm{M}$, pengerjaan trotoar yang baru hanya $1 \mathrm{~km}$ tersebut tersangkut minimnya anggaran 12 Miliar.

Perbaikan jalan khatib Sulaiman merupakan bagian dari rencana Pemerintah Kota Padang agar tidak lagi menjadi penyumbang kemacetan. Gambaran suatu perkotaan atau perubahan pembangunan terhadap kota berdasarkan dan berorientasi pada waktu luang dengan kegunaan untuk kepedulian terhadap warga kota. Median jalan di pangkas nantinya median di jalan di perkecil menjadi satu meter sehingga jalan menjadi lebar, untuk mewujudkan masyarakat sebagai kota pendidikan, unggul serta berdaya saing dalam perdagangan. Mampu menciptakan 
lingkungan yang sehat dan polusi bakal berkurang dan meningkatan kualitas udara kota.

Upaya pelebaran Jalan Khatib Sulaiman dilakukan untuk mengatasi masalah macet pada jam-jam sibuk, disamping itu juga membangun penerangan jalan umum yang terencana, dan memperbaiki semua fasilitas trotor yang terlihat rancak dan nyaman agar masyarakat sering menggunakan Trans padang dan beraktivitas dengan berjalan kaki tapi tersedianya fasilitas yang ada masih sedikit masyarakat yang menggunakannya.

Selain itu, untuk membuat penerangan jalan umum yang rencananya di pasang di setiap tengan atau sisi jalan, akan dilakukan perbaikan trotoar yang terlihat nyaman sehingga masyarakat akan lebih sering menggunakan jalan kaki dan angkutan umum seperti trans padang namun sedikit masyarakat yang berpatisipasi dalam menggunakan fasilitas pedestrian dan ikut berpatisipasi untuk mengurangi faktor terjadi kemacetan seperti parkir di sepanjang jalan khatib sulaiman kota Padang.

Tersedianya areal parkir tetapi tidak di manfaatkan adalah dengan berupaya memakai konsep akses ke pemilikan atau perpakiran langsung. Pemilik kendaraan biasanya enggan parkir jauh dari tempat tujuan sehingga jika hendak menyediakan parkir harus sedekat mungkin dengan pemilik kendaraan atau tujuan.

Mengingat masih banyak warga kota yang parkir tidak pada tempat yang telah ditentukan.

Merujuk Peraturan daerah Kota Padang nomor 11 Tahun 2005 tentang ketertiban umum dan ketentraman masyarakat Tertib jalan dan angkutan jalan larangan pasal 2 ayat (3) memarkir kendaraan bermotor atau tidak bermotor di jalan trotoar (4) memakai jalan dan atau trotoar untuk kepentingan pribadi atau kelompok yang menghambat kelancaraan lalu lintas (5) menumpuk bahan-bahan bangunan atau benda-benda lain diperinikan jalan atau di atas trotoar. Pasal 3 ayat (5) setiap orang dilarang membuang benda-benda apapun, kotoran binatang/manusia, sampah/ plastik di jalan, di trotoar atau di selokan.

\section{TINJAUAN PUSTAKA \\ Implementasi}

Implementasi adalah proses kegiatan atau pengerjaan dari sebuah rancangan yang yang tersusun secara rapi. Implementasi biasanya dilakukan setelah perencanaan sudah dianggap bagus. Pengertian Implementasi adalah sesuatu hal yang berproses pada tindakan, kegiatan, aksi, mengikut sertakan mekanisme dari suatu sistem, Implementasi tidak hanya kegiatan menonton tetapi merupakan suatu proses yang terencana secara baik yang berfungsi untuk mencapai hal yang di inginkan. (Usman : 2002).

Pressman dan Wildavsky (1984) implementasi didefinisikan sebagai korelasi antara pembuat keinginan dengan sarana action untuk mencapai tujuan tersebut, atau kemampuan untuk membangun dalam hubungan antara yang diinginkan dengan cara untuk mencapainya. (Tangkilisan, 2003: 17).

Pengertian Implementasi kebijakan menurut Patton dan Sawaciki (dalam Tangkilisan, 2009: 9) adalah sebagai berikut: "Implementasi terkait berbagai kegiatan yang bertujuan melaksanakan program, dimana pada posisi ini badan pelaksana berperan aktif dalam mengatur, menafsirkan dan melaksanakan kebijakan yang sudah di pilih.

Dalam pelaksaan implementasi untuk mencapai acuan yang akan di laksanakan yaiu: pelaksanaan dalam wujud strategi atau melalui menyusun turunan dari latihan umum, langkah tersebut membutuhkan pendekatan untuk kegiatan yang dilaksanakan.

Implementasi kebijakan berhubungan dengan prosedur dimana setelah permasalahan ada masuk di dalam sebuah agenda maka berbagai opsi di rancang dan melakukan berbagai hal dalam pengupayakannya. Selanjutnya pemerintah mencoba malakukan perubahan terhadap 
kebijakan dan menerapkannya. Beberapa proses dalam implementasi yaitu proses menekankan bagaiaman terlaksananya secara mulus dari sasaran yang sudah di targetkan.

Suatu tindakan yang berubahn menjadi kesepakatan dalam tindakan operasional elama periode waktu tertentu atau dalam konteks upaya berkelanjutan untuk mencapai perubahan signifikan dan kecil yang terhubung oleh keputusan. Perlu ditekankan bahwa tahap implementasi kebijakan ini tidak akan dimulai sampai tujuan dan proposal ditentukan atau di identifikasi oleh keputusan kebijakan. Dengan demikian, tahap penerapan dimulai hanya setelah undang-undang tersebut berlaku dan dana dialokasikan untuk membiayai pelaksanaan kebijakan tersebut.

\section{Pembangunan}

Siagian (1994: 20) sebagai keinginan untuk mewujudkan kehidupan masyarakat dan warganya. Seringkali pembangunan yang berjalan adalah pembangunan yang harus berjalan adalah kemajuan berpendidikan. Maka dari itu pembangunan diwujudkan sebagai perubahan yang di capai oleh masyarakat di bidang perekonomian. Sangat dibutuhkan keseimbangan politik .(Tjokroamidjojo, 1985: 87).

Pembangunan merupakan keinginan dan rancangan usaha pertumbuhan dan perubahan yang terencana yang dikerjakan secara sadar oleh suatu Negara, pemerintah mengupayakan modernisasi dalam rangka pembinaan suatu bangsa (nation building). Suatu proses yang berjalan selalu yang akan dilaksanakan, tonngak pencapaian dapat dilakukan melalui tahap-tahap tertentu. Penahapan itu berupa berdasarkan periode waktu tertentu, anggaran, atau hasil tertentu yang diharapkan untuk dicapai.

Pembangunan merupakan pelaksanaan yang dilakukan secara berencanaan dan perencanaan itu berorientasi pada pertumbuhan dan percobaan, melakukan perubahan secara terbaru melakukan perbaikan aparatur serta pelaksana dari pemerintah dan juga berarti perbaikan dari pelaksana usaha pembanguna. Inti dari pembangunan sebagai proses pengendalian usaha yang di inginkan pemerintah untuk suatu Negara untuk mewujudkan pertumbuhan yang sudah di rencanakan menuju suatu kondisi yang lebih baik dan ingin memajukan di dalam berbagai bentuk kehidupan bangsa.

Pembangunan yang telah dilaksanakan oleh seluruh komponen masyarkat sesuai dengan potensi yang dimilikinya perlu diawasi pelaksanaan dan kesinambungannya.dari tahap perumusan, implementasi dan evaluasi, umpan balik diberikan selama proses berlangsung. Pengawasan tidak hanya milik mutlak pemerintah, tetapi seluruh komponen masyarakat berhak ikut serta pengawasan sesuai kepasitasnya masing-masing. Hal ini harus dilakukan agar pembangunan yang di rencanakan dan dilaksanakan memberikan manfaat yang sebesar-besarnya bagi masyarakat. pengawasan dilakukan untuk mengatasi terjadinya kebocoran atau kegagalan dari semua tahapan pembangunan, yang pada akhirnya menjamin manfaat yang sebesar-besarnya bagi masyarakat.

\section{Pedestrian}

Pedestrian sebagai untuk prioritas untuk pejalan kaki seharusnya mempunyai rasa safety dan nyaman terhadap masyarakat yang sedang berjalan kaki. Keamanan disini terwujud dalam bentuk pembatasan jalan berupa peninggi trotoar, penggunaan pagar pohon dan penggunaan street furniture. Selain pengguna yang ingin merasakan aman, dimana mereka harus merasa nyaman jalur pedestrian harus memiliki menyegarkan pikiran karena hal itu menunjang kenyamanan dan keinginan masyarakat untuk berjalan kaki saat menggunakan jalur trotoar sebagai jalur mereka yang telah disediakan. Penyedian jalur pedestrian (Flora, 2009) adalah :

1) Konektivitas, yaitu terintegrasinya jalur pedestrian secara utuh; 
2) Aksesibilitas, yaitu ketersedian jalur yang lebar, serta kualitas permukaan;

3) Keamanan, ketersediaan tempat penyeberangan dan pencahayaan;

4) Kenyamanan.

Jalur Pedestrian harus memberikan keamanan dan kenyamanaan bagi pejalan kaki, keamanan disini dapat diekspresikan dalam bentuk interpolasi trotoar, menggunakan pagar pemisah pohon dan menggunakan aksesories luar ruangan. Selain itu, warga juga perlu merasa nyaman saat berjalan menggunakan jalur pejalan kaki sebagaimana rutenya.

Pedestrian merupakan pemberian fasilitas untuk masyarakat berupa ruang public. Fungsinya tidak hanya tempat reakreasi pejalan kaki dengan taman kota, tetapi juga sebagai sarana edukasi dan sosialisasi warga kota. Untuk mengurangi kemacetan kota, ini juga sering terjadi di Indonesia, karena masyarakat lebih suka menggunakan kendaraan pribadi untuk transportasi, kegagalan pemerintah menyediakan alat transportasi yang efisien dan efektif mengurangi tekanan pada angkutan umum.

Fungsi jalur pedestrian pada daerah perkotaan adalah :

1) Sebagai fasilitas penggerak bagi para pejalan kaki;

2) Sebagai media interaksi sosial;

3) Sebagai unsur pendukung, keindahan dan kenyamanan kota.

Anggriani (2009:9), fasilitas jalur Pedestrian harus memenuhi prinsip keselamatan (keamanan) dan confort (nyaman). Keselamatan berarti keamanan pedestrian dari kecelakaan dan gangguangangguan khusus oleh kendaraan umum yang merupakan penyebab banyaknya utama banyak kecelakaan pedestrian akibat tercampurnya fungsi jalan setapak dengan kegiataan lainnya.

Konsep pedestrianisasi dalam perencangan ruang kota antara lain:

a) Pedestrianisasi dapat menumbuhkan aktifitas yang sehat sehingga mengurangi kerawanan kriminalitas; b) Pedestrianisasi dapat meransang berbagai kegiatan ekonomi, sehingga dapat mendukung perkembangan kawasan ekonomi, sehingga dapat mendukung perkembangan kawasan bisnis yang menarik;

c) Pedestrianisasi sangat menguntungkan sebagai ajang kegiatan promosi, pameran dan kampanye;

d) Jalur pedestrian merupakan daerah yang menarik untuk kegiatan sosial, berekreasi dan lain-lain;

e) Pedestrinisasi mampu menghadirkan suasana dan lingkungan spesifik, unik dan dinamis di lingkungan pusat kota;

f) Berdampak positif terhadap upaya penurunan tingkat pencemaran udara dan suara.

\section{METODE PENELITIAN}

Jenis penelitian ini adalah kualitatif menurut Suamadinat (2005: 60) adalah suatu penelitian yang berkaitan dengan pendeskripsian fenomena, peristiwa, kegiatan social perilaku, keyakinan, persepsi, pemikiran orang secara perorangan, maupun kelompok. Adapun penilitian ini adalah deskriptif penilitian yang bertujuan untuk menentukan pemecahan masalah yang ada berdasarkan data yang tersedia.

Proses penelitian kualitatif ini melibatkan upaya-upaya penting, seperti mengajukan pertanyaan-pertanyaan dan prosedur-prosedur, mengumpulkan data yang spesifik dari para partisipan, menganalisis data secara induktif mulai dari tema-tama khusus sampai tema-tema umum, dan menafsirkan makna data.

\section{HASIL DAN PEMBAHASAN Implementasi Kebijakan Pedestrian Jalan Khatib Sulaiman Kota Padang}

Berdasarkan temuan di lapangan yang telah diuraikan sebelumnya, tahap implementasi Peraturan Daerah kota padang nomor 11 tahun 2005 tentang ketertiban umum dan ketentraman 
masyarakat. Pemerintah kota Padang membangun perbaikan pedestrian demi mengatasi persoalan kemacetan, pemerintah kota Padang membangun pedestrian agar masyarakat bisa menggunakan fasilitas atau aksesoris yang telah disediakan untuk menggurangi kendaraan bermotor.

Kebutuhan fasilitas pejalan kaki biasanya terfokus di daerah perkotaan, mengingat kehidupan masyarakatnya yang cukup banyak, terutama di tempat-tempat keramaian seperti pusat perbelanjaan, stasiun, terminal, sekolahan, dan lain sebagainya. Tujuan dari jalur Pedestrian adalah sebagai obyek alami dan obyek bantuan yang dapat dilalui oleh manusia.

Temuan penelitian ini didukung Edwars dan Sulistyastuti (2015:85-87) mempertimbangkan dalam mengimplementasikan kebijakan :

\section{a) Komunikasi}

Komunikasi salah satu faktor penunjang kebijakan-kebijakan suatu sampel tujuantujuan ide-ide yang digunakan oleh pemerintah sehingga dapat diterima dengan jelas oleh masyarakat.

Suatu kebijakan harus di komunikasikan dengan tepat, akurat, dan konsisten. Komunikasi yang diperlukan agar aparat mengerjakan pekerjaan sesuai tugas yang telah di berikan dalam melaksanakan suatu kebijakan dalam bekerja. Pemerintah kota Padang memberikan kebijakan dengan melakukan rapat yang perlu komunikasi yang baik seperti pelaksanaan pembangunan pedestrian adanya beberapa instansi yang bergabung, seperti Dinas Pekerjaan Umum dan Penataan Ruang kota Padang, Dinas Perhubungan kota Padang, Satpol PP.

Implementasi Pembangunan Pedestrian Jalan Khatib Sulaiman kota Padang

a. Jalur pedestrian

Pusat tempat yang biasanya manusia melakukan kegiatan denga berjalan kaki di pusat kota, terletak di pusat kota yang memudahkan masyarakat berpindah-pindah dengan menggunakan berjalan atau kendaraan umum sebagai aksesoris kelengkapan trotoar.

b. Kegiatan jalan

Tempat manusia dimana melakukan kegiatan ke tempat yang di inginkan perlengkapannya yang diperuntukkan bagi lalu lintas, yang berada pada permukaan tanah, ruang untuk pemberian untuk pengguna terhadap pengguna pejalan kaki sehingga dapat meningkatkan kemudahan beraktivitas dalam kegiatan sehari-hari.

c. Walkability

Suatu pandangan untuk memberikan suatu kawasan yang ditunjang oleh fasilitas yang lengkap dan dapat dicapai hanya dengan berjalan kaki. Diberikan fasilitas yang lengkap agar masyarakat kota Padang tidak lagi mengendarai kendaraan pribadi seperti kursi, sampah, halte dan tempat nyuci tangan.

d. Kenyamanaan

Jalur setapak merupakan salah satu pemberian prasarana bentuk berupa jalan raya untuk pejalan kaki. Oleh Karena itu, sebaiknya digunakan untuk kegiatan pejalan kaki bukan kegiatan lain seperti kendaraan yang parkir berdagang karena hanya dapat tidak memberikan keamanan dan membahayakan keselamatan. kenyamanan jalan setapak seperti trotoar harus menjadi keutamaan saat merencanakan transportasi perkotaan.

e. Prinsip Perencanaan

Memberikan rancangan, baik dari aspek pembentukan pembangunan dalam lingkungan, ketercapaian terhadap lingkungan dan kawasan, maupun sistem transportasi, berpikir ke depan mengenai jalannya kegiatan yang akan dilakukan dengan mempertimbangkan segala faktor yang terkait dan ditujukan kepada sasaran tertentu dan terukur yang telah ditetapkan sebelumnya.

f. Fasilitas Pedestrian 
Tersedianya kondisi trotoar ataupun aksesoris di dalam pembuatan pedestrian khatib sulaiman yaitu: trotoar, tempat penyeberangan, tempat bunga, lampu penerangan, tempat duduk, pemasangan bollard, tempat sampah, papan informasi rambu lalu lintas, halte, tempat berkebutuhan khusus.

\section{b) Sumber Daya}

Suatu penerapan yang bentuk dalam pelaksanaan terlibat berbagai orang-orang seperti pemerintah ataupun instansi-instansi yang terkait tertentu akan memberikan dampak terhap pelaksana.

Sumber daya tersedia aparatur pemerintah dalam pengawasan dan penertiban dalam pengawasan pedestrian jalan khatib sulaiman kota Padang. Sumber daya sangat di perlukan dalam pengimplementasikan suatu kebijakan perumpaman yang menghubungkan dengan waktu, anggaran atau dana dan tenaga manusia. Dalam melaksanakan kebijakan tentu memerlukan anggaran dalam mencapai tujuan. Pentingnya area pedestrian pada sebuah area aksesoris kota dapat memberikan suatu hal yang signifikan yang harus dipikirkan oleh pemerintah.

\section{c) Disposisi}

Kecenderungan-kecenderungan salah satu faktor yang mempengaruhi suatu organisasi pemerintah dalam menjalankan tugas sesuai dengan peraturan yang digerakkan dalam mempengaruhi tingkat pendidikan. Keinginan pemerintah kota Padang dalam mewujudkan kebijakan dalam keinginan agar mewujudkan masyarakat madani.

\section{d) Struktur Birokras}

Struktur organisasi yang bekerja bersama dalam implementasi organisasi berpengaruh pada organisasi, organisasiorganisasi, suatu pengerjaan yang bekerja sesuai dalam skillnya sama untuk mencapai suatu yang diinginkan. Implementasi kebijakan tahapan teknik-teknik yang bekerja secara sama untuk di mencapai tujuan.

Implementasi kebijakan tahapan yang sangat penting dalam struktur kebijakan. Struktur prosedur-prosedur kerja dalam implementasi kebijakan pedestrian jalan khatib sulaiman sudah (SOP) standar operating procedurs menyeragamkan tindkan-tindakan dari pejabat terhadap pelaksanaan tugas yang diberikannya dalam segi pembuatan fasilitas.

\section{PENUTUP}

Implementasi pembangunan pedestrian jalan khatib sulaiman kota Padang peraturan daerah kota Padang Nomor 11 tahun 2005 tentang ketertiban umum dan kententraman masyarakat masih belum terimplementasikan masih belum optimal. Problem kemacetan yang masih terjadi, masih sering terjadi masyarakat yang masih parkir di sekitar pedestrian khatib sulaiman kota Padang walaupun sudah ada larangan, masyarakat yang jarang menggunakan fasilitas pedestrian karena panas yang belum tertutup dengan pepohonan yang rindang Tujuan dari pemerintah kota Padang untuk membangun pedestrian Jalan khatib sulaiman kota Padang ke depan adalah mewujudkan masyarakat yang berpendidikan, saling menghargai, perdagangan dan pariwisata yang sejahtera, religious dan berbudaya untuk pembangunan pedestrian tersendiri masih terbengkalai karena masalah anggaran yang berkurang.

Agar implementasi pembangunan pedestrian jalan khatib sulaiman kota Padang terlaksana sangat di butuhkan dukungan dari masyarakat agar mematuhi aturan yang telah ada, masyarakat harus sering menggunaka fasilitas pedestrian di jalan khatib sulaiman kota Padang karena pemerintah kota Padang sudah memberikan fasilitas publik agar berkurangnya kemacetan yang sering terjadi di dalam permasalahan kota, agar polusi udara berkurang, hidup jauh lebih sehat dengan berjalan kaki. 


\section{DAFTAR KEPUSTAKAAN}

Anggara, Sahya \& Sumantri, (2016). Administrasi Pembangunan Teori dan Praktik. Bandung: CV Pustaka Setia.

Anggriani, Niniek (2009). Pedestrian Ways Dalam Perancangan Kota. Surabaya: Yayasan Humaniora.

Basrowi \& Suwandi, (2008). Memahami Penelitian Kualitatif. Jakarta:PT Rineka Cipta.

Akib, Haedar. (2010). Implementasi Kebijakan: Apa, Mengapa dan Bagaimana Jurnal Administrasi
Publik, Volume 1 No. 1 Thn. 2010.

Rahmi \& Khadiyanta (2018). Kajian Kualitas dan Tingkat Pelayanan Jalur Pedestrian di Koridor Jalan Khatib Sulaiman Kota Padang. Jurnal Teknik $P W K$ Vol 7(4), 2018, 223-232. EISSN: $\quad 2338-3526 \quad$ Terhadaap Kepuasaan \& Kenyamanan Pejalan Kaki di Pusat Kota Manado. Media Matrasain.

Peraturan Daerah Kota Padang No. 11 Tahun 2005 tentang Ketertiban Umum dan ketentraman masyarakat. 